\title{
Microgeographical Patterns of Schistosomiasis and Water Contact Behavior; Examples from Africa and Brazil
}

\author{
Helmut Kloos*, Andréa Gazzinelli*/+, Paul Van Zuyle**
}

\begin{abstract}
Departamento de Enfermagem Materno Infantil e Saúde Pública, Escola de Enfermagem, Universidade Federal de Minas Gerais, Av. Alfredo Balena 190, 30130-100 Belo Horizonte, MG, Brasil *Department of Epidemiology and Biostatistics, School of Medicine, University of California, San Francisco, California, 94143, USA **National Center for Geographic Information and Analysis, University of California, Santa Barbara, California, USA
\end{abstract}

This paper examines the results of spatial (microgeographical) water contact/schistosomiasis studies in two African (Egyptian and Kenyan) and one Brazilian communities. All three studies used traditional cartographic and statistical methods but one of them emploeyd also GIS (geographical information systems) tools. The advantage of GIS and their potential role in schistosomiasis control are briefly described. The three cases revealed considerable variation in the spatial distribution of water contact, transmission parameters and infection levels at the household and individual levels. All studies showed considerable variation in the prevalence and intensity of infection between households. They also show a variable influence of distance on water contact behavior associated with type of activity, age, sex, socioeconomic level, perception of water quality, season and availability of water in the home. Water contact behavior and schistosomiasis were evaluated in the Brazilian village of Nova União within the context of water sharing between household and age/sex groups. Recommendations are made for further spatial studies on the transmission and control of schistosomiasis.

Key words: schistosomiasis - water contact behavior - geographical aspects - Brazil - Egypt - Kenya

Spatial, epidemiological and ecological information is important for the control of schistosomiasis because all three components of the life cycle (humans, the parasite and snail intermediate hosts), must converge in space and time at suitable water bodies for transmission to occur. Thus, intensity of infection is influenced considerably by the frequency, duration and intensity of human contact with infective water. Spatial studies of schistosomiasis, snail intermediate hosts and water resources have been carried out at both the macrogeographical (world-wide, regional, national and district) (Hunter 1981, Doumenge 1987, Kloos et al. 1988, Bavia et al. 1994, Malone 1994) and

\footnotetext{
This work was supported by Small Grants/TDR/UNDP/ World Bank/WHO; Pró-Reitoria de Pesquisa da Universidade Federal de Minas Gerais; Fundação de Amparo à Pesquisa do Estado de Minas Gerais-Fapemig; Conselho de Desenvolvimento Científico e TecnológicoCNPq; Programa de Apoio a Grupos de ExcelênciaPronex/CNPq/Finep; National Institutes of Health-NIH/ Grant AI26505.

${ }^{+}$Corresponding author. Fax: $+55-31-226.7735$. E-mail: andreag@dourado.enf.ufmg.br

Received 4 May 1998

Accepted 31 August 1998
}

microgeographical (community) levels (Kloos et al. 1983,1997, Lima e Costa et al. 1985, Kloetzel 1989, Barreto 1991). Although they use data of different levels of aggregation and specificity, these two types of study can complement each other. The objective of the majority of water contact studies has been to evaluate exposure risk levels in populations as part of epidemiological and immunological studies but they may also be used to identify transmission sites, to assess the need for an optimal location of improved water supplies and sanitary facilities, for the development of health education programs and to monitor and evaluate control programs (WHO 1979, Kloos et al. 1983). The new GIS (geographic information systems) tools allow analyses at different scales and they are vastly more versatile than traditional cartographic techniques but have so far been limited to macro-geographical analyses with the exception of the study by Van Zuyle (1995). The development of GIS tools is giving new impetus to spatial studies of schistosomiasis and other tropical diseases by providing the means for interactive mapping and analysis of the distribution of snails, infection in humans and environmental and intervention parameters. Persisting problems in using GIS regularly and optimally include lack of collaboration with sectors outside the health field, unreliability of many data bases, lack of map boundary data 
(longitudinal and latitudinal) (Mott et al. 1995) and loss of trained GIS health manpower into the privatte sector.

Two methods have been used to collect water contact data: direct observation and interviews. The advantages and disadvantages of both methods have been reviewed (WHO 1979, Gazzinelli et al. 1997) and the appropriateness of their use must be considered in each study community or area, although they may be used in combination. For spatial studies it is preferable to use mostly empirical data from studies using the direct observation method due to the general unreliability of interview data for mapping purposes.

The objective of this paper is to review microgeographical studies of schistosomiasis and water contact behavior in three communities and areas in Egypt, Kenya and Brazil. These examples illustrate some of the achievements, challenges and opportunities for water contact studies toward schistosomiasis control in individual communities.

\section{MATERIALS AND METHODS}

The materials and methods used for each study are briefly summarized below. The studies are discussed in chronological sequence.

\section{RESULTS}

El Ayaisha, Egypt - In the Upper Egyptian village of El Ayaisha, where schistosomiasis haematobium is endemic, water contact behavior of a cohort group of 392 male students aged 5-16 years was studied as part of an epidemiological study designed to evaluate age-specific and site specific risk behavior. Only boys living in the village during the entire study period, and who had birth certificates (over $90 \%$ of the male student population), were included in the study. Female students were excluded for cultural reasons in this Moslem community. Twelve observers monitored and recorded all water contact at 12 observation sites on the Nile and three canals daily during 7day surveys in July, October and March between 1978 and 1980. They recorded time of entry into and exit from the water, age and sex, the parts of the body exposed, type of activity and the contact site used for each person. Person-specific and household level socioeconomic and water use data were obtained during interviews in the homes of all cohort members. The extensive irrigated fields could not, however, be studied. An exposure index: TBM (total body minutes: number of contacts per person $x$ percent area of body exposed $x$ duration of contact) was used. Body exposure was calculated from clinical burn charts. Malacological surveys and sentinel snail and hamster exposure studies were carried out at most contact sites dur- ing each July and October, when transmission occurred, and cercariometric filtration was performed in June 1980 (Kloos et al. 1982a, 1983).

Mapping of geometric mean egg counts showed values to be nearly twice as high in the eastern than the western section of the village with clusters of highly infected individuals along the three canals and lighter infectiond and uninfected individuals nearer to the Nile. Similar patterns were noted again seven months post-chemotherapy of all school children (Kloos et al. 1983) reflecting differences in transmission levels as established by the biological and cercariometric surveys (Fig. 1) and water contact patterns.

This study documented that the geography of water contact changes with the age of school aged children. While the number of water contacts increased with age, the proportion of boys using exclusively the canals decreased. Boys aged 5-7 used mainly the canals, due to their close proximity to their homes and their relative safety for swimming, but more than half of the boys in this age group were not seen in the water (Fig. 2). With increasing age boys traveled farther within the community, engaged in more activities, especially swimming and drawing water, and they increasingly avoided the relatively dirty canals. Thus they came increasingly into contact with the Nile. Few 14-16 year olds used the relatively dirty canals (Fig. 3). Whereas mean canal TBM values of individuals decreased from 61.3 among 6-8 year olds to 30.0 in 14-16 year olds, Nile TBM increased from 114.6 to 153.9 in the same ages. The common perception that the canals were dirty from human and animal use and contained much "bilharzia" and that the Nile's water as the traditional life support for Egypt was clean with little or no schistosomiasis explains to a large degree the preference of its water for domestic and recreational purposes (Kloos et al. 1982b). The fact that the Nile is a major source of schistosomiasis haematobium and increasingly also schistosomiasis mansoni points out the need for health education. The highest risk group were 12-13 year old boys, who had both the highest geometric mean egg counts (14.8) and the highest TBM values (Kloos et al. 1983).

More than half of all households owned one or two types of alternative water sources, deep wells and chlorinated piped water from the Nile. They were used mainly for making brick, watering animals, cleaning the house and bathing but not for cooking or drinking (for which they used untreated Nile water) due to their high salt contents. Most laundering was done by groups of women at the Nile and the larger canals for social reasons and because of their preference for adequate and chemi- 


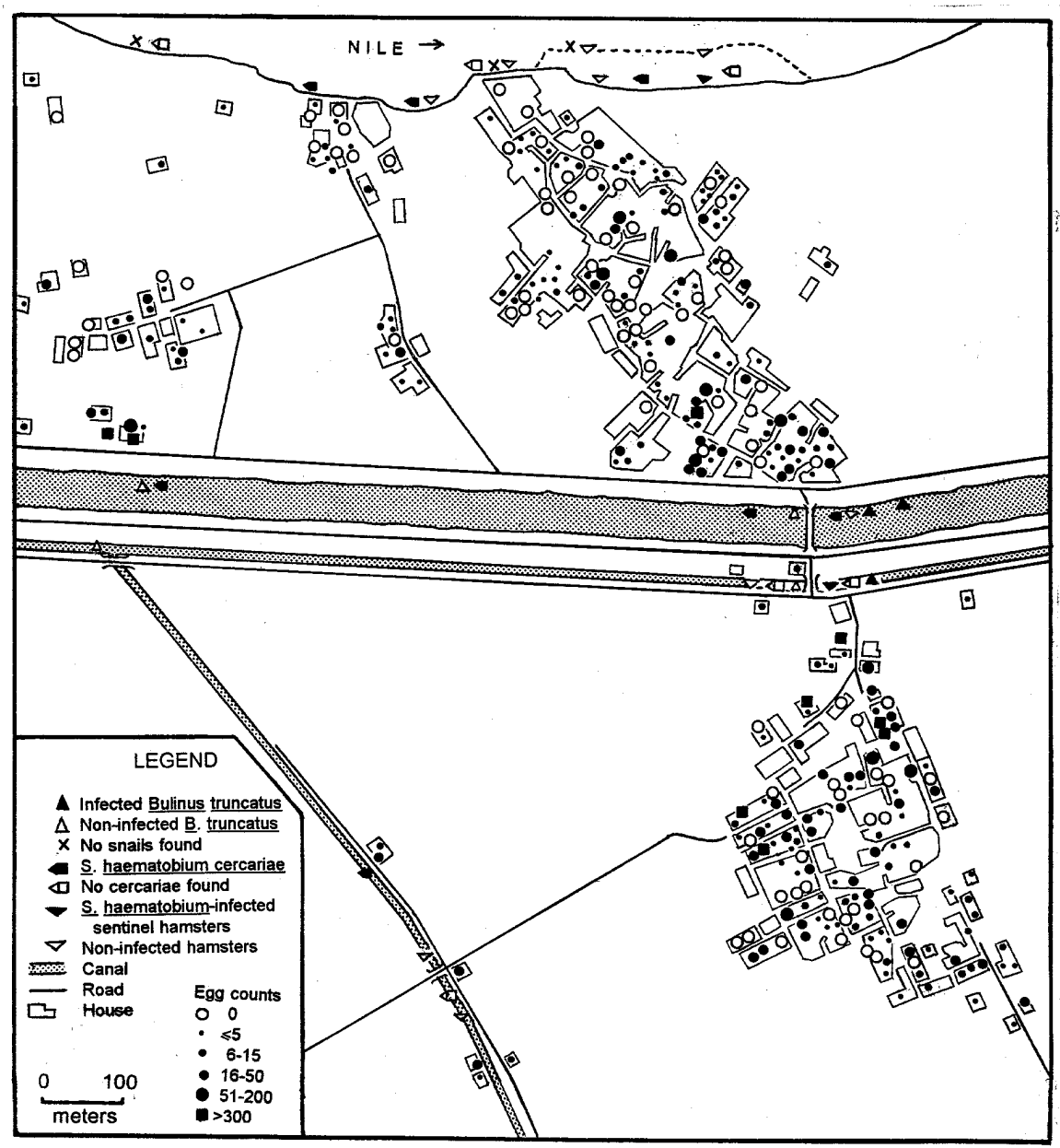

Fig. 1: El Ayaisha, Egypt: Schistosoma haematobium geometric mean egg counts of 367 student cohort members aged 5-16 years and Bulinus truncatus snails, S. haematobium cercarie and sentinel hamsters in the Nile and the three major canals (based on Kloos et al. 1983).

cally soft water for washing clothes. This spatial pattern indicates possibilities for the development of community laundry units that provide ample water and good drainage in conjunction with health education.

Discriminant analysis correlating egg counts with infected and non-infected water contact sites and frequency of water contact correctly classified $71.4 \%$ of the $6-10$ year olds by category of site. The discriminant function accurately predicted $84.2 \%$ of those with most frequent contact in noninfected sites. Similar results were obtained for the 6-12 age group (Kloos et al. 1983).

Van Zuyle (1995) analyzed a subsample of the El Ayaisha cohort using a gravity model, which predicts interactions between two places as a function of distance and the "size" of the origin and destination (Cordey \& Wilson 1971) and GIS. This simple model was developed by plotting the sum of observed TBM at each water contact site for each person who visited that site against the distance to his home. Using logistic transformation of distance data gave significant results $(\mathrm{P}<0.01)$. He compared the observed TBM (Fig. 4) and predicted (modeled) TBM values for each individual (Fig. 5) by plotting the residuals of the model using the perspective surfaces technique. Perspective surfaces are (in addition to the point and line map displays presented in this paper) another cartographic technique providing different visual perspective views of the same data. The central valley in the differences surface (Fig. 6) represents an area of local underprediction by the model, while the peaks on both sides show where the model overpredicted the actual values. A purely aggregate measure of the explained and unexplained variance would not be able to describe the local differences within the data set that this image shows. Color overlays of water contact sites and places of residence, different views of the TBM 


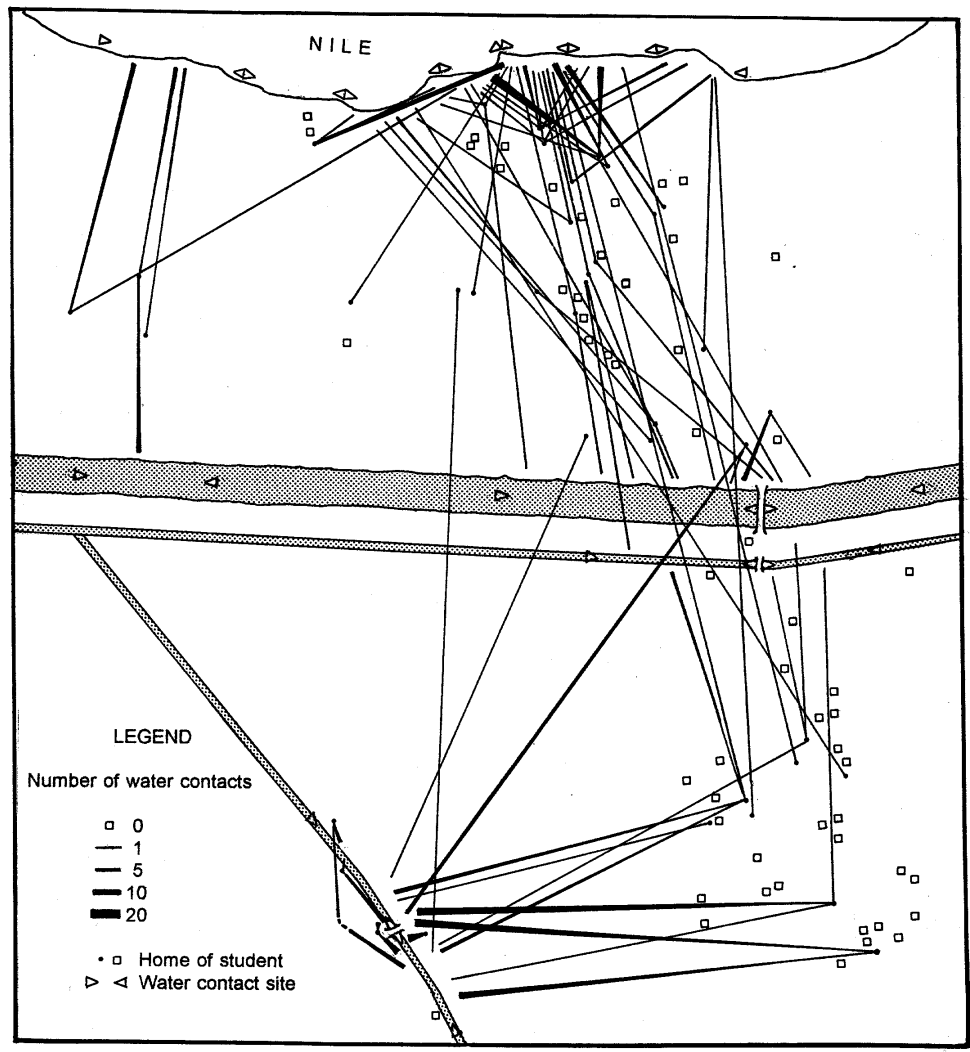

Fig. 2: El Ayaisha, Egypt: frequency of water contact of 95 cohort members aged 5-7 years at the 14 contact sites in relation to their homes (based on Kloos et al. 1983).

surface, or the display of infection levels instead of TBM can provide additional insights into the relationship between water contact and schistosomiasis. The perspective surface cartographic technique is not only an alternative way of visualizing the data and the model, but is also a statistical measure. Standard statistical tests of difference may be applied to the dfference surface.

Kangundo, Kenya - The water contact behavior in four small adjacent rural areas (named here Areas A, H, S and W) in Kangundo Location in Machakos District, Kenya, was studied in 198385 as part of an immunological study using traditional cartographic and statistical techniques. The focus of the study was on evaluating the role of distance, water contact, and transmission variables in Schistosoma mansoni infection. Between $70 \%$ and $79 \%$ of the population above 17 years of age was infected in the four areas, and 53\%-61\% of the below 17 group. By including the study of both man-snail and snail-man transmission this study aimed to provide broad understanding of the role of water contact in schistosomiasis infection (Kloos et al. 1997).

Six local observers recorded the water contact behavior of the total population monthly at 57 stream sites by rotating between sites according to a balanced design. Each area contained one or more streams transmitting schistosomiasis. The 588 dispersed households were aggregated in 120 clusters to enhance mapping and visualization of the spatial data. All water contact duration data were weighted on the basis of body exposure, time of day, use of soap (which is cercariacidal), and use of hand-dug seepage holes in the stream alluvium at each site. These weightings strengthened the correlation with infection. Quantitative stool examinations (Katz et al. 1972) of all local persons were done in 1984. All individual egg counts were transformed to $\log (x+1)$ and aggregated at the household cluster level for analysis and mapping.

Snail collections were made biweekly at all sites studied for water contact. Cercarial densities were calculated from weekly and monthly filtrations at the contact sites. Methods used are described by Sturrock et al. (1994).

A transmission index, defined as $\mathrm{TI}=\mathrm{wD} / \mathrm{nxS}$, where $\mathrm{wD} / \mathrm{n}$ is the mean duration of exposure per person and $\mathrm{S}$ the number of Biomphalaria pfeifferi snails infected with $S$. mansoni snails at the same 


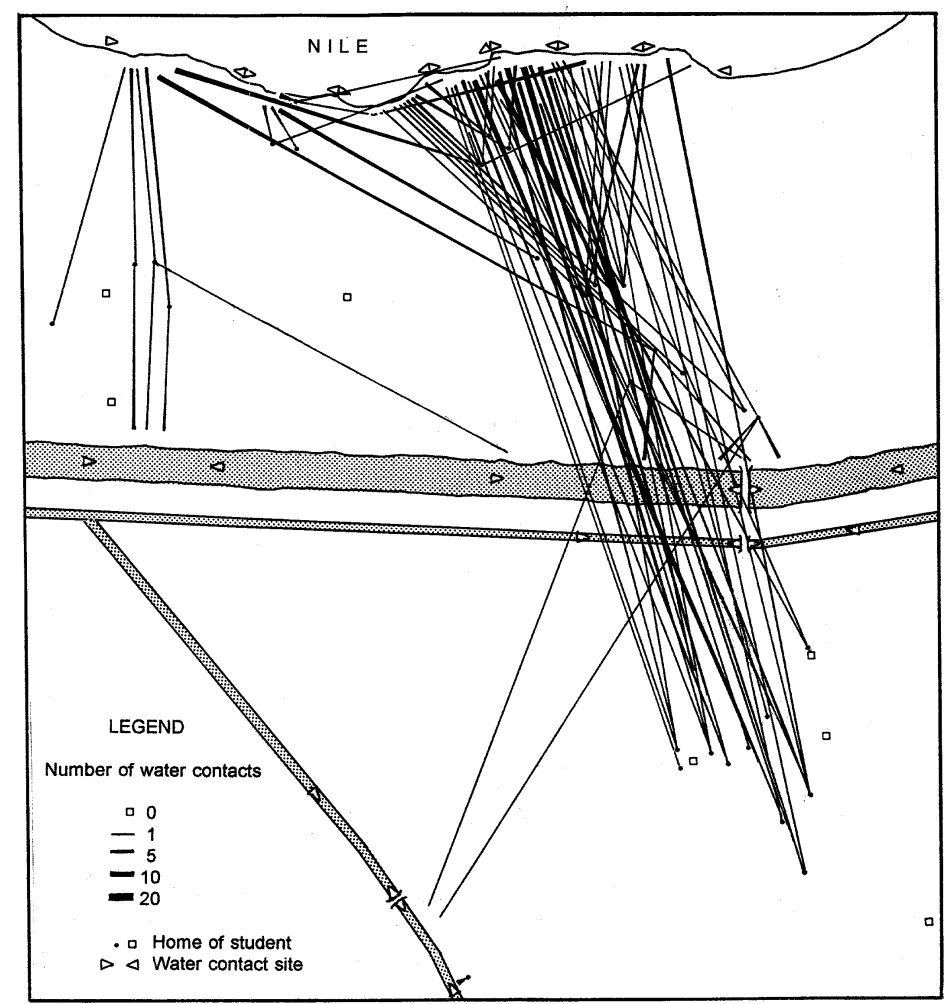

Fig. 3: El Ayaisha, Egypt: frequency of water contact of 38 cohort members aged 14-16 years at the 14 contact sites in relation to their homes (based on Kloos et al. 1983).

sites, was used to evaluate snail-man transmission. A potential contamination index, defined as $\mathrm{PCI}=(\mathrm{wDxE}) / 1000$, where $\mathrm{wD}$ is mean weighted duration of exposure per person and $\mathrm{E}$ is $\log (\mathrm{x}+1)$ of geometric mean egg counts, was employed together with total number and total (weighted duration) of contact to examine man-snail transmission. Total number and duration of water contact were calculated from the household cluster data for each contact site.

Maps were prepared at the 1:1,000 and 1:5,000 scales from aerial photographs showing all streams, roads and houses. The straight line method was used to measure distance from household clusters to water contact sites.

Results showed that water contact varied considerably between the four areas and between household clusters. Individual household clusters used between one and 14 contact sites, with most contact taking place at the nearest or the three nearest sites to the homes of users (Fig. 7). Older persons used a larger number and more distant sites than children, mainly when traveling for occupational and social purposes. Frequency and duration of contact declined slowly with distance, apparently due to the relatively short distances be- tween homes and the stream sites $(40-500 \mathrm{~m})$.

When subdividing the four study populations further into persons under 17 years of age and above 17 years, mean frequency of contact per person was the variable most strongly correlated with geometric mean egg counts in multivariate logistic stepwise regression analysis in both the above and below 17 age groups in Areas A and in the below 17 group Area S, the transmission index (TI) in both age groups in Area W and distance to the most frequently used site in the older group in Area $\mathrm{H}$. The three distance variables (distance to the nearest site from individual households, distance to the site most frequently used per household and mean distance per water contact) were mostly inversely correlated with egg counts (Figs $8,9)$. These differences between the four areas, similar to the significant differences in S. mansoni prevalence rates in another area in Brazil (CouraFilho et al. 1997), re-emphasize the need for caution in generalizing from the results of single community surveys.

Stepwise regression of the transmission variables, which could be carried out only in Area $\mathrm{H}$ due to incompleteness of the data base in the other three areas, also identified the number of infected 


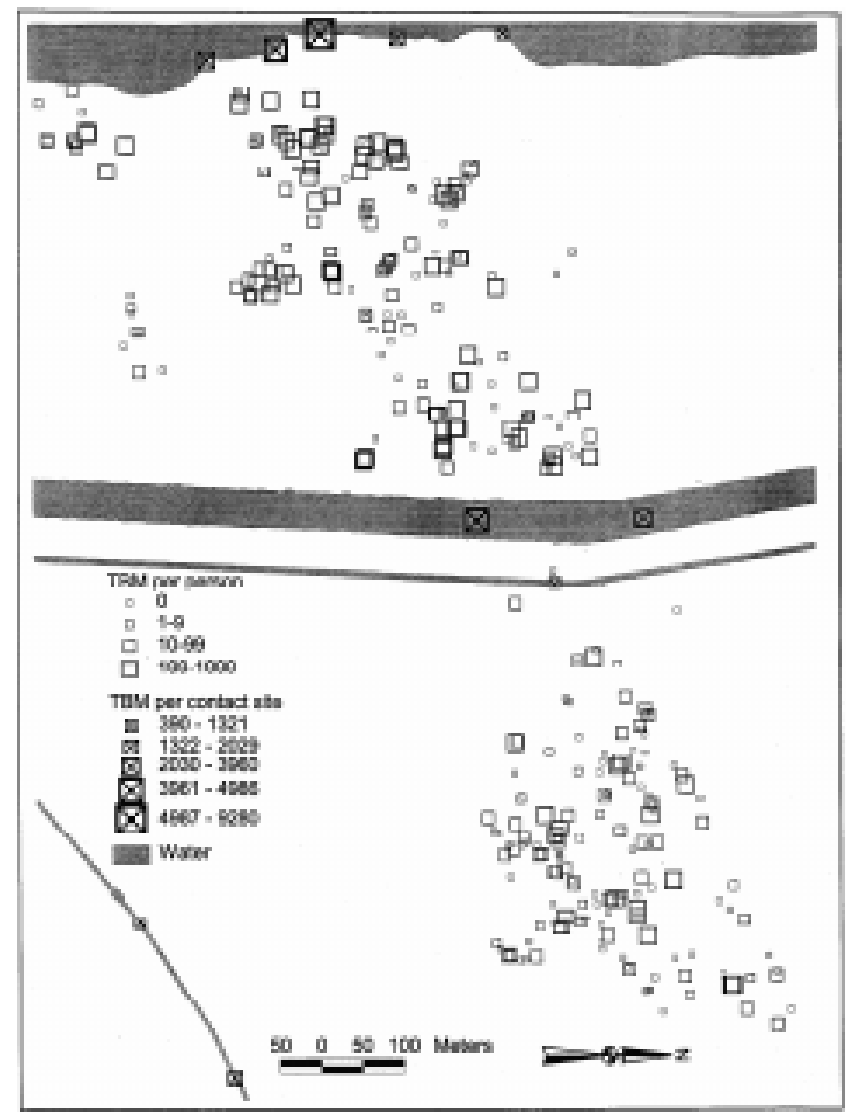

Fig. 4: El Ayaisha, Egypt: actual TBM (total body minutes) exposure of 339 cohort members at 10 contact sites in relation to their homes using geographical information systems tools (based on Van Zuyle 1995).

snails per contact site as the predominant manto-snail transmission variable and number of contacts as the strongest predictor $(\mathrm{P}<0.0001)$. Number of contacts was also the main predictor of number of $B$. pfeifferi and number of cercariae $(\mathrm{P}<0.003)$ (Fig. 8).

Nova União, Brazil - In the small rural village of Nova União, in the northern State of Minas Gerais, Gazzinelli et al. (1998) carried out water contact, domestic water use and KAP studies surrounding schistosomiasis and exposure risk with the objective of identifying high-risk behaviors and examining domestic water supply problems. A health education and water supply intervention are being planned in close collaboration with the local municipality. Here we summarize preliminary findings on the relationship between schistosomiasis and water contact behavior among owners and nonowners of semi-improved water supplies and on spatial patterns. Twenty-four of the 39 households included in the study had their own household water supply (wells, protected springs, plastic pipe connections from natural springs and one unprotected spring) and 15 households depended on neighbors who had a water supply at home or on the streams (Gazzinelli et al. 1998). Seventy-two percent of Nova União's population were infected with $S$. mansoni in 1992, before the first project chemotherapy, and $58.1 \%$ at the end of 1996 , one year after the third round of chemotherapy (Fig. 10; Rodrigo Corrêa-Oliveira, pers. commun.).

The water contact situation in Brazil differs from that in most of Africa for two major aspects, namely (1) the predominance of private, fenced land in Brazil tends to restrict access to streams and other potential transmission sites, and (2) widespread ownership of private water supplies further limits the observability of water contact behavior. It was thus necessary to use in the statistical analysis data from supplemental household interviews gathered concurrently with the direct observation data.

All water contact with 12 sites along the two local streams, the unprotected spring and three fish ponds were observed and recorded for seven days each in July and November 1996 and in February 


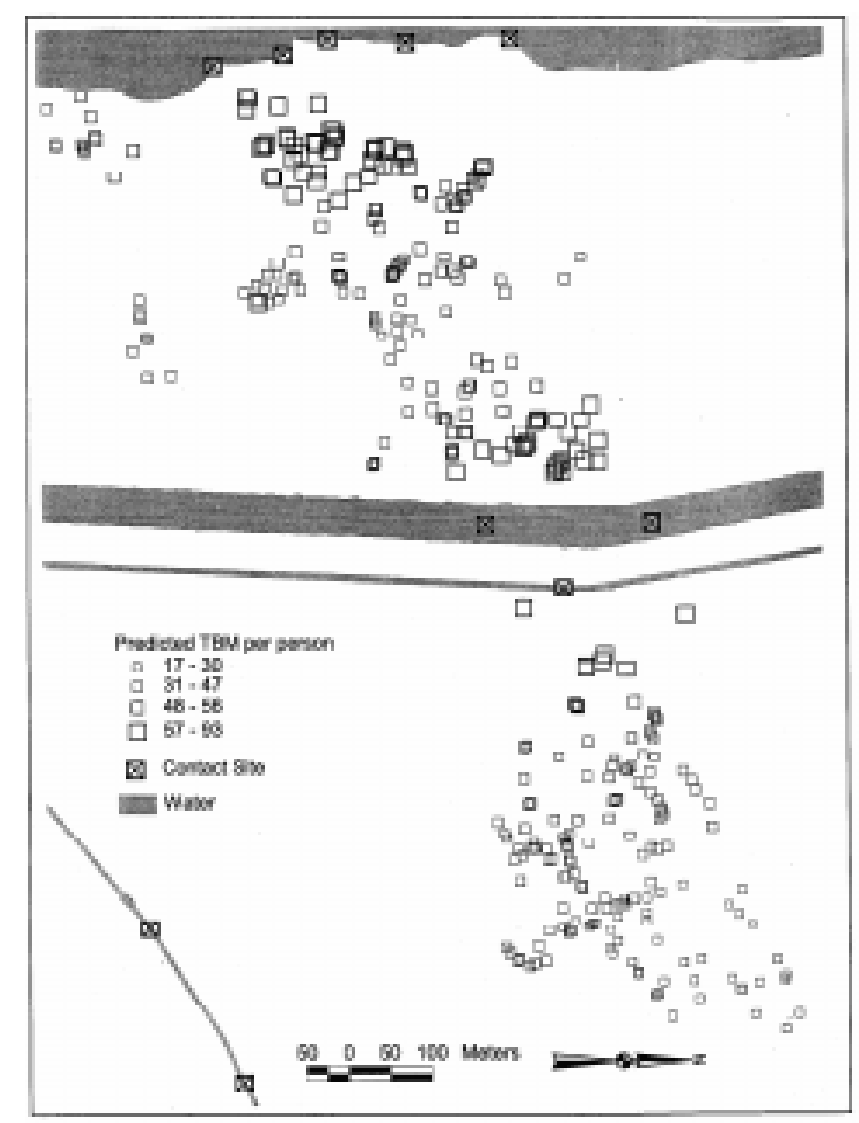

Fig. 5: El Ayaisha, Egypt: predicted TBM (total body minutes) exposure of 339 cohort members at 10 contact sites in relation to their homes using geographical information systems tools (based on Van Zuyle 1995).

and July in 1997. Data from the first three surveys are reported here. All these sites contained $B$. glabrata, including infected specimens from several stream sites, a fish pond and the unprotected spring. None of the wells and protected springs was found to contain $B$. glabrata during five repeated surveys and they were excluded from the analysis. In addition to observing the usual water contact parameters, observers also recorded the amount of water drawn (in liters) from sources outside the home for home use. One hundred and twenty-four of the nearly 200 persons living in Nova União in 1996 were examined for schistosomiasis using the Kato-Katz method (Katz et al. 1972) and included in the study. Details of the methodology are presented by Gazzinelli et al. $(1997,1998)$.

Results show that the water contact patterns in Nova União are more complex than indicated by earlier studies using the interview method exclusively (Lima e Costa et al. 1991, Coura-Filho et al. 1994) for five reasons: (1) most households lacking a water supply obtained most or all their water from neighbors or relatives free of charge; they used the streams mainly for washing clothes and utensils; (2) eleven households with their own supply used the streams for domestic activities, mainly for washing clothes and utensils, and eight households used the wells, springs and piped outlets of other households, mainly because they preferred their water for cooking, drinking or other purposes or because their own supplies were inadequate; (3) all the households lacking their own supply or those with a supply and borrowing from other households were located on the slope away from the stream, where wells yielded less water and its quality was inferior (salty) to that of sources along the stream, indicating the importance of the hydrological environment in water use (Fig. 11); (4) the number of water contacts, particularly contacts for washing clothes and utensils at the distant stream sites decreased by more than $30 \%$ during the rainy season (February-March), when the streams carried large amounts of soil; and (5) the eight households which either constructed new wells, laundry sites, latrines and showers or installed an electric pump in their well during the 1-year study period increased their use of well water and de- 


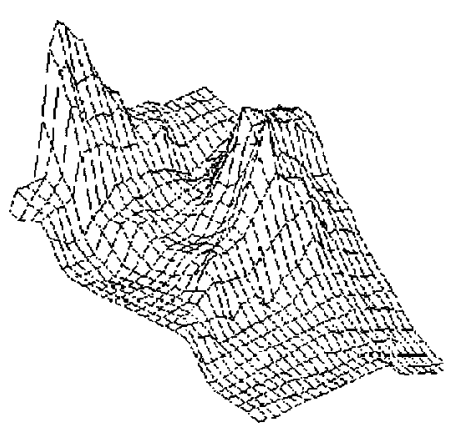

Predicted
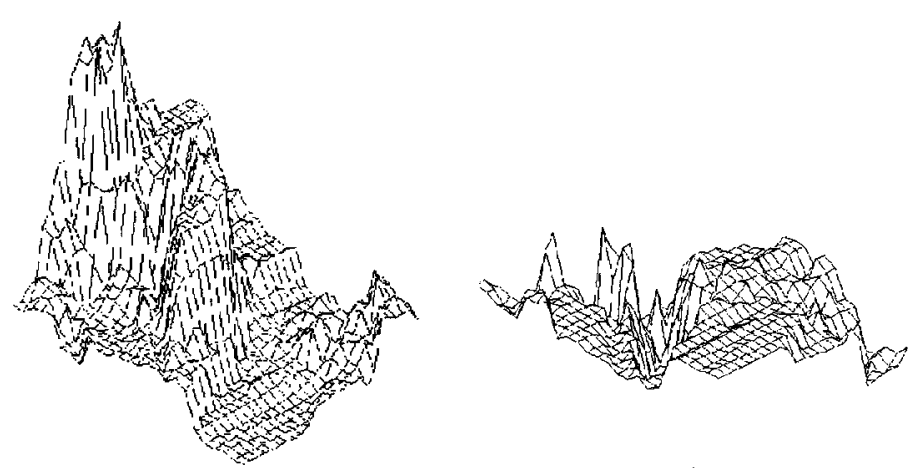

Difference

\section{Observed}

Fig. 6: El Ayaisha, Egypt: perspective surfaces of TBM (total body minutes) exposure of 339 cohort members using geographical information systems tools: predicted TBM (based on Fig. 5), observed TBM (based on Fig. 4) and the differences between the two. Based on Van Zuvle 1995.

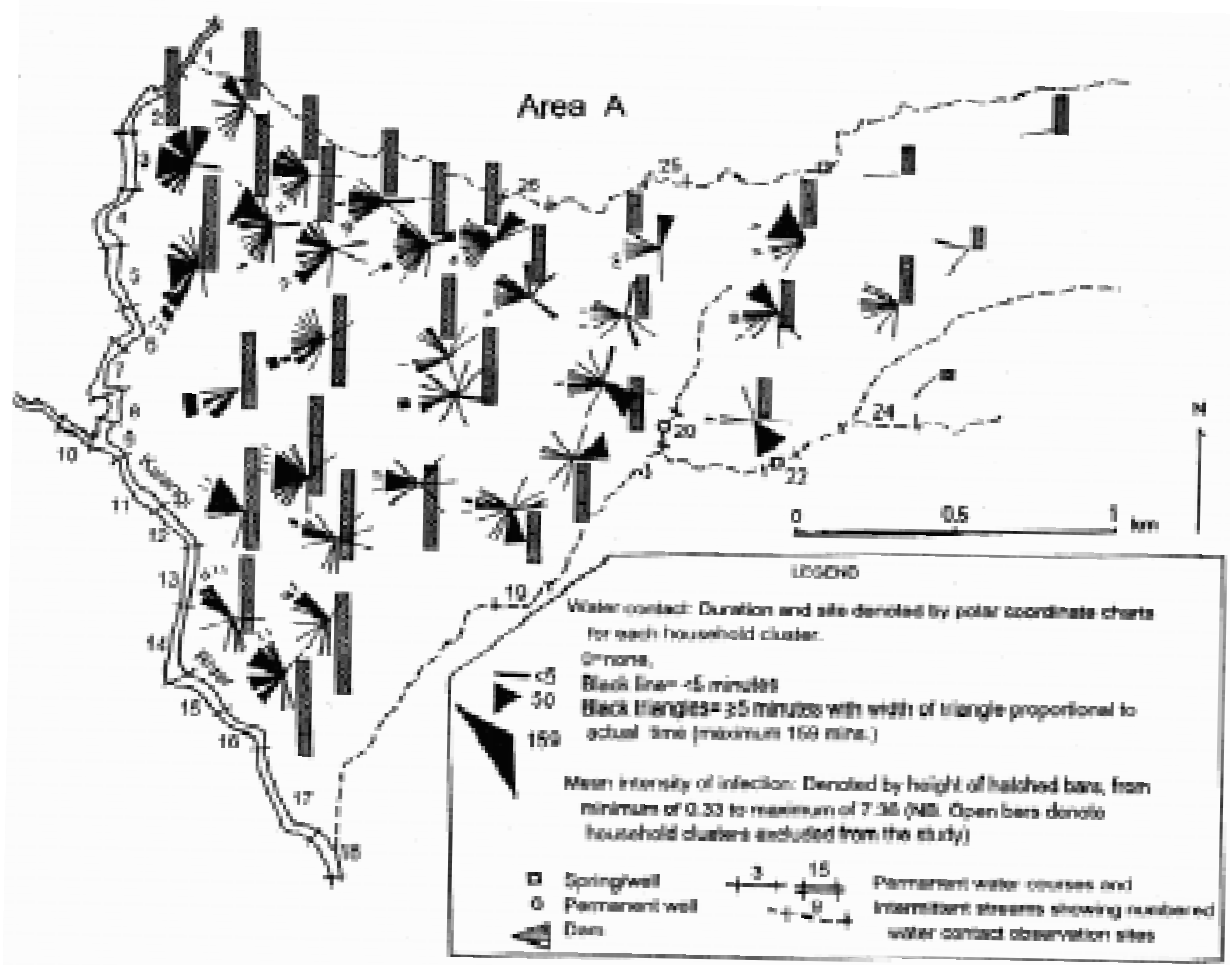

Fig. 7: Kangundo area, Kenya: mean intensity of Schistosoma mansoni infection per household cluster based on log $(\mathrm{x}+1)$ of age standardized geometric mean egg counts and mean duration of site-specific water contact per individual in Area A.

creased the use of the streams showing a dynamic water use pattern.

Several additional spatial patterns in water contact and infection relevant to control could be identified: (1) the straight-line distance between homes and water contact sites ranged from $8-80 \mathrm{~m}$ for most activities, particularly drawing water. Washing clothes and utensils, as well as crossing streams and fishing by children were observed as far away as $350 \mathrm{~m}$. Women washed clothes in groups for social interactions. Most fishing contacts by older persons were reported to take place at greater distances, mostly in other communities with larger streams; (2) nearly all stream contacts took place at sites upstream from the village and very few, mostly by children, within the village, reflecting preference for cleaner water than the sewage-polluted stream within the village (Fig. 11). The longer distances traveled for washing clothes and utensils, usually by groups of women, suggests that community laundry facili- 


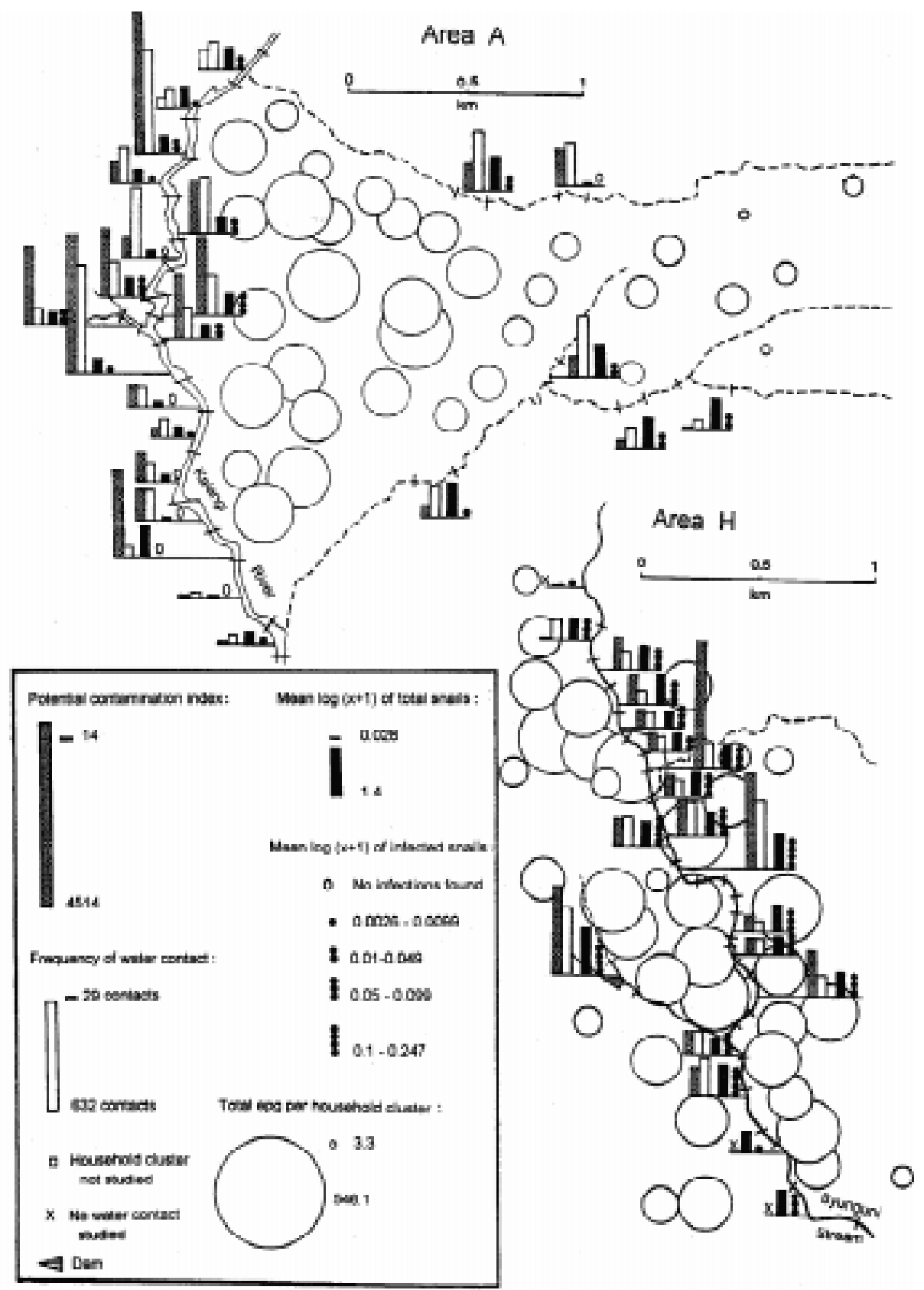

Fig. 8: Kangundo area, Kenya: potential contamination index, mean $\log (\mathrm{x}+1)$ of total infected snails and of Schistosoma mansoniinfected snails, by contact site, and total frequency of water contact and geometric mean egg counts per household cluster in Areas $\mathrm{A}$ and $\mathrm{H}$.

ties would be acceptable in Nova União if they can provide adequate water and provide appropriate facilities that would prevent drainage problems; current by the municipality call for the installation of more costly individual facilities. In the regression analysis egg counts were inversely (but not significantly) correlated with distance between houses and the nearest stream site.
Mapping of egg counts by age group, sex and presence or absence of household water supplies revealed a fairly random distribution, although mean egg counts and uninfected persons clustered in several households (Fig. 10). More pronounced clustering of both heavily infected and non-infected persons and households was recorded in nearby Boa União, a larger, more affluent village, charac- 

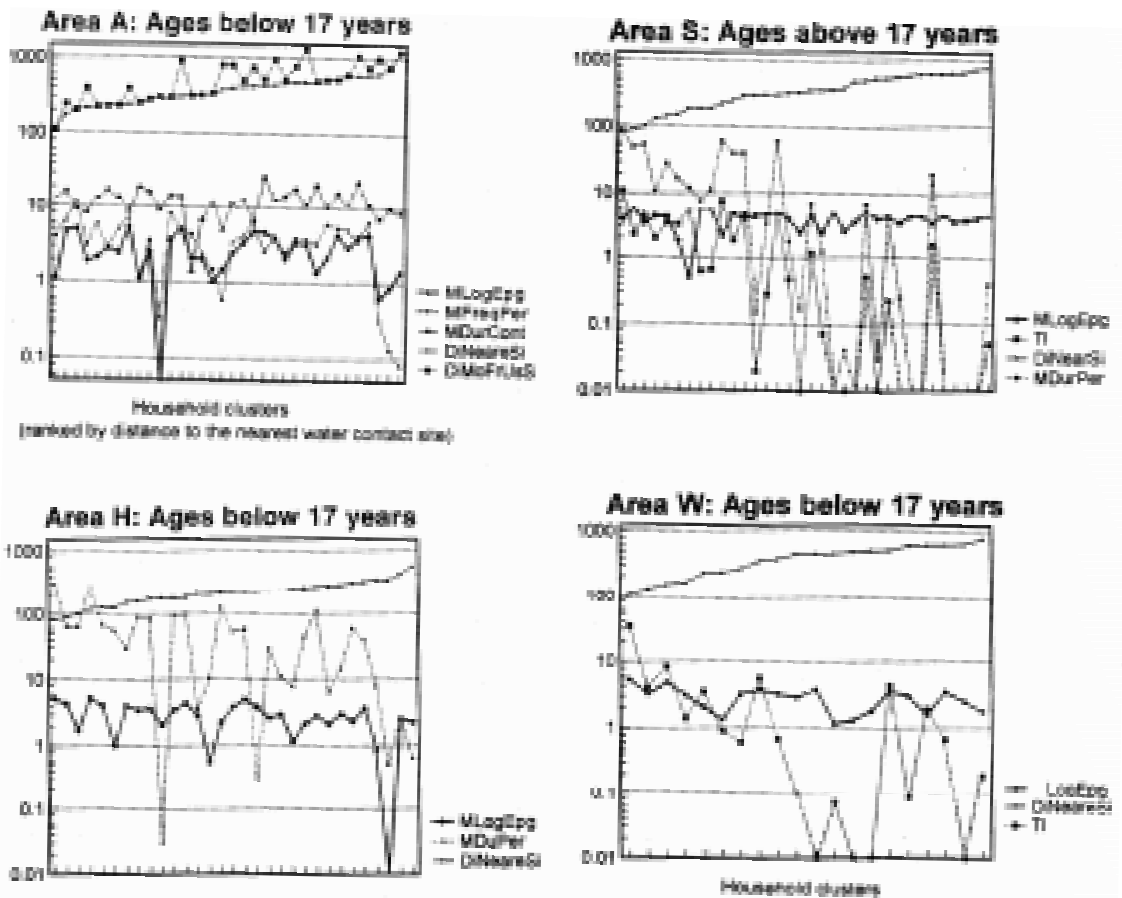

Fig. 9: Kangundo area, Kenya: relationship between Schistosoma mansoni infection [ $\log (\mathrm{x}+1)]$, distance (in meters) and independent variables significantly correlated $(\mathrm{p}<0.05)$ in stepwise regression: mean frequency of contacts per person $(\mathrm{MFreqPer})$, mean duration per person (MDurPer), mean duration per contact (MDurCon) (all duration values in minutes), mean number of sites used per person (MNSiUsPer) and distance to the most frequently used site (DiMoFrUsSi), by age and study area.

terized by greater socio-economic differentiation than Nova União. Moreover, households with a water supply had lower mean egg counts when three individuals with very high counts were excluded $(\mathrm{P}<0.05)$ and had lower prevalence of Ascaris $(\mathrm{P}<0.0002)$ and Ancylostoma $(\mathrm{P}<0.053)$ infection. Households with a water supply were relatively more affluent than those without and had less frequent and less intensive exposure to the streams than households lacking a water supply (Fig. 11).

In the stepwise linear correlation analysis of geometric mean egg counts $\log (\mathrm{x}+1)$ and 23 water contact, socioeconomic and demographic variables generated by the direct observation and interview methods, only frequency of fishing $(\mathrm{R}=0.3095$, $\mathrm{P}<0.0005)$ and washing parts of the body $(\mathrm{P}<0.0018)$, which typically takes place during the trip from the fields, were significantly associated with egg counts in the total population. The low correlation coefficient for the ten most highly correlated independent variables $(\mathrm{R}=0.5046)$ indicates the low predictive power of the model. In a subsample of 51 children aged 4-18 years, frequency of agricultural work $(\mathrm{R}=0.5408, \mathrm{P}<0.0001)$ and household income $(\mathrm{P}<0.032)$ were the strongest predictors of egg counts, and the multiple correlation coefficient for the ten strongest vari- ables was 0.7563 (Gazzinelli et al. 1997). These relatively weak correlations appear to be due primarily to the water contact activities that could not be observed because they occurred outside the study area, particularly fishing, agricultural work, crossing of streams and the associated activities washing parts of the body and bathing.

\section{DISCUSSION}

This paper shows that microgeographical analyses using either traditional cartographic and statistical analyses or GIS techniques can reveal variable and complex relationships between water contact behavior, exposure risk, transmission dynamics and schistosomiasis infection at the community level. The case studies summarized here also indicate progress made in spatial studies at the community level in recent years, use of various cartographic techniques and microgeographical analyses, and identify possible applications of these studies for schistosomiasis control.

Three spatial aspects of water use appear to be particularly relevant for schistosomiasis control in Brazilian communities: (1) the use of multiple water sources as a form of coping behavior in communities with substandard water supplies and the social network of sharing household water; (2) the variable influence of distance on water use for dif- 


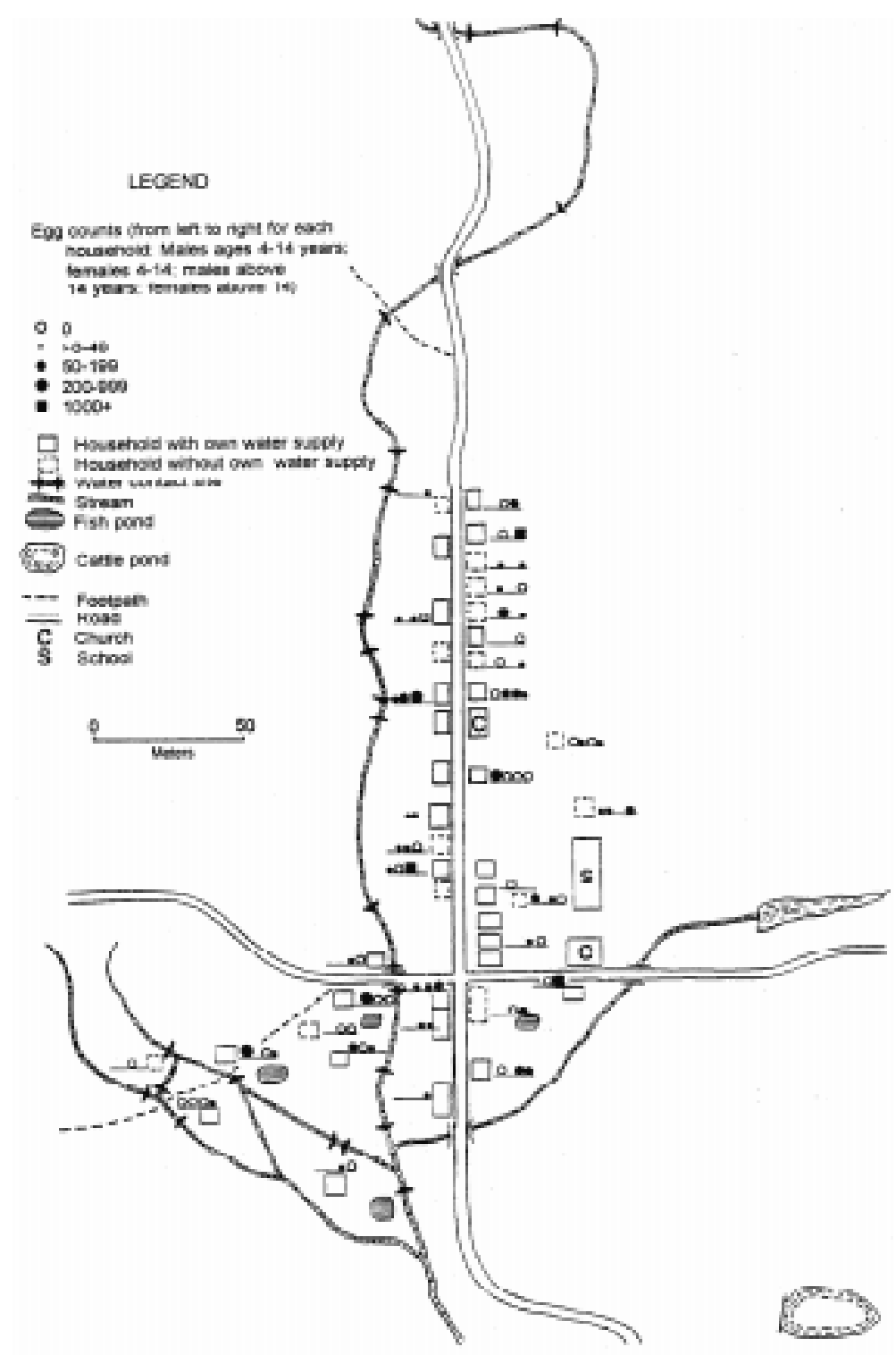

Fig. 10: Nova União, Brazil: distribution of arithmetic mean egg counts by household, age and sex in relation to the water contact sites studied.

ferent domestic activities; and (3) age and sex specific clustering of $S$. mansoni egg counts in certain households, a pattern also found in the neighboring village of Boa União (Kloos et al. unpublished data) that was unrelated to water contact patterns, which points to immunological and possibly genetic factors (Butterworth et al.1988, Bethony et al. 1997). Reliable information on multiple uses of different water sources with known transmission levels, social networks and distance relationships can contribute to identifying high risk behavior of individuals and groups. When combined with information on knowledge, attitudes and practices surrounding household water sources, this information may facilitate health education programs. Spatial studies of the distribution of schistosomiasis cases and water contact can play a major role in Brazil's national schistosomiasis control program as it is becoming increasingly concerned with the identification and control of residual transmission foci (Kloetzel 1989). Mapping of water contact, especially activity-specific contact, can elucidate distance relationships more precisely than mere data aggregation. Spatial analysis can contribute to a better understanding of these patterns and thus assist in the planning and implementation of water 


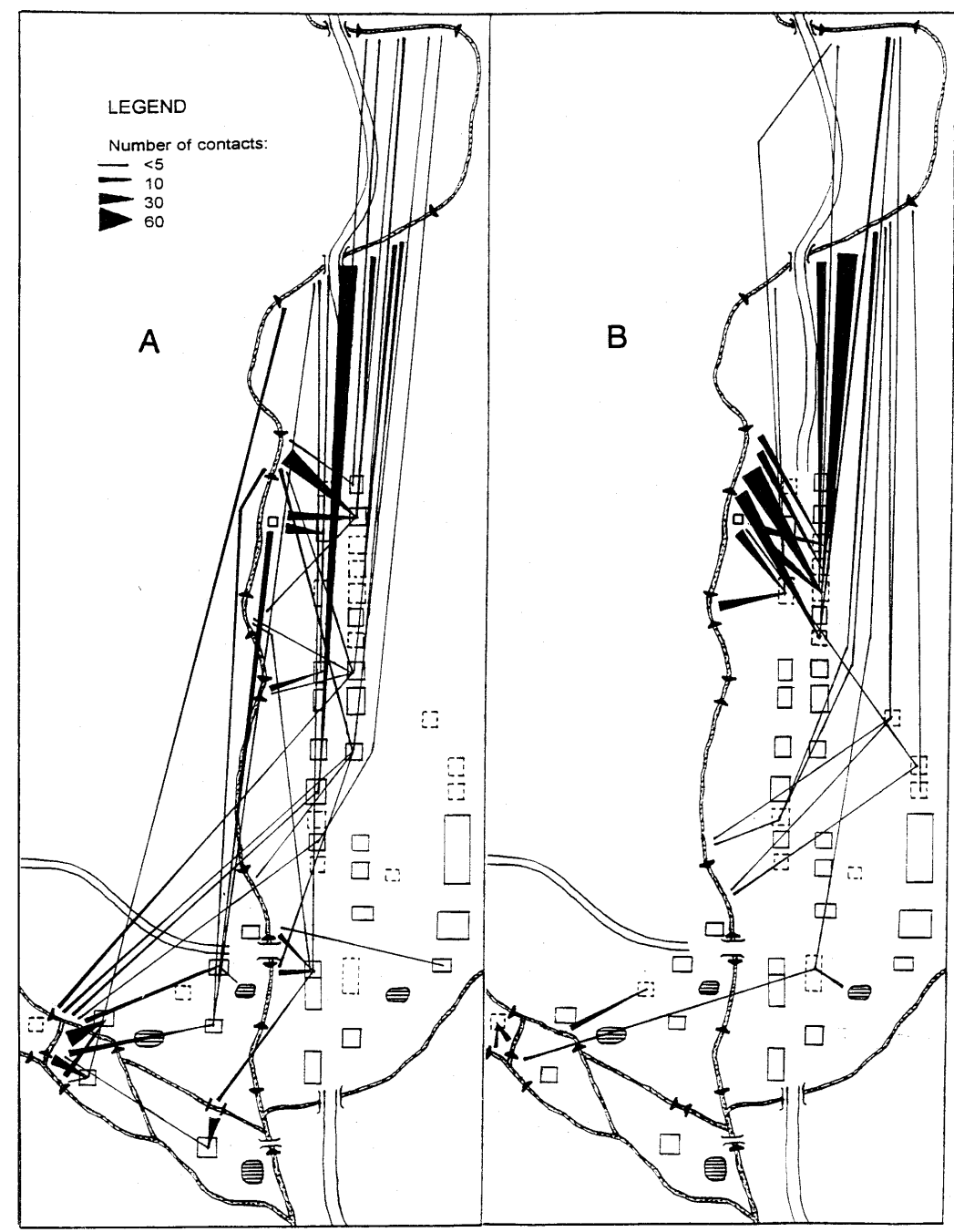

Fig. 11: Nova União, Brazil: frequency of water contact with the stream contact sites by (A) households with their own water supply and (B) households without a water supply.

supply systems and schistosomiasis control programs. Although there exist similarities in the water contact and infection patterns between the African and Brazilian communities, each program aiming to reduce water contact with infective water through water supplies and health education must consider underlying socioeconomic, cultural and community-specific factors. White et al. (1972) came to similar conclusions in their comprehensive study of geographic, socioeconomic and infrastructure factors in water use in relation to water-related diseases in different East Africa societies.

Use of GIS can facilitate spatial analyses and permit more rapid interactive analysis and querying of data bases. The manually drafted maps presented here show a large amount of detail of the spatial relationship between water contact, trans- mission parameters and infection. Nevertheless, they must be considered preliminary and limited in scope since these static maps do not allow the analyst to change a wide variety of parameters and assumptions or query individual attributes while at the same time viewing patterns of observed or modeled behavior on rapidly produced maps as is now possible with GIS. It is this iterative process of seeing the data in the light of different model parameters, categorization schemes, symbols, colors, scales and other variations which can lead to a completely different understanding than that acquired from a static map (Clarke et al. 1996).

There is a need in the future for GIS generated models of schistosomiasis at the community level that include additional parameters, such as type of water contact activity, socioeconomic factors and 
perception of the quality of water of different water bodies to more completely predict water contact behavior. A recent review of the literature identified a large number of behavioral, socioeconomic, environmental, administrative and political factors in schistosomiasis transmission and control (Kloos 1995), many of which may be mapped and modeled at the community, district or national levels.

This study shows that the direct observation method is appropriate and essential for spatial interaction studies of water contact behavior and schistosomiasis at the microgeographical level. The general absence of official statistics at the household level and the unreliability of interviews in locating and documenting place locations make direct observation particularly useful. However, its usefulness is limited to small villages or neighborhoods of towns where most water contact of the study population with infective sources can be observed (Gazzinelli et al. 1997).

\section{ACKNOWLEDGEMENTS}

To Elsevier Science for permission to publish modified versions of Figs 1-3 and 7-9, which were originally published in Social Science and Medicine 17: 545-562 and 44: 949-968. To Dr Rodrigo Correa Oliveira for technical assistance.

\section{REFERENCES}

Barreto ML 1991. Geographical and socioeconomic factors relating to the distribution of Schistosoma mansoni infection in an urban area of north-east Brazil. Bull WHO 69: 93-102.

Bavia ME 1996. Geographic Information Systems for Schistosomiasis in Brazil, $\mathrm{PhD}$ Thesis, Louisiana State University and Agricultural and Mechanical College, Baton Rouge, Louisiana, $135 \mathrm{pp}$.

Bavia ME, Hale L, Malone JB 1994. Geographic information systems for control of schistosomiasis in Bahia, Brazil (abstract). Am J Trop Med Hyg Suppl 53: 220 .

Bethony JM, Thakur AN, Alves Oliveira A, Silveira MAS, Pizziolo VR, Correa-Oliveira R, Gazzinelli G, LoVerde PT 1977. Familial agregation of antibody isotype responses to defined and crude Schistosoma mansoni antigens in an endemic community in Brazil. Abstracts of the 6th International Symposium on Schistosomiasis, Belo Horizonte, p. 106.

Butterworth AE, Fulford AJC, Dunne DW, Ouma JH, Sturrock RF 1988. Longitudinal studies on human schistosomiasis. Philos Trans R Soc London B 321: 495-511.

Cordey H, Wilson AG 1971. Spatial interaction. SocioEconomic Planning and Science 5: 73-95.

Coura-Filho P, Rocha RS, Farah MW, Silva GC, Katz N 1994. Identification of factors and groups at risk of infection with Schistosoma mansoni: a strategy for the implementation of control measures. Rev Inst Med Trop São Paulo 36: 245-253.

Coura-Filho P, de Souza CP, Farah MWC, Coelho PMC
1997. Risk of transmission of schistosomiasis in Parque Estadual do Rio Doce (PERD) - MG-Brazil, and its surroundings: 1 . Spatial distribution of the prevalence in Dionisio, MG. Abstracts of the 6th International Symposium on Schistosomiasis, Belo Horizonte, p. 132.

Clarke CK, McLafferty SL, Tempalski B 1996. On epidemiology and Geographic Information Systems: a review and discussion of future directions. Emerg Infect Dis 2: 85-92.

Doumenge JP 1987. World Health Organization Atlas of the Global Distribution of Schistosomiasis, Presses Universitaires de Bordeaux, Bordeaux, 398 pp.

Gazzinelli A, Cadete MM, Souza MCC, Nascimento I, Kloos H 1998. Domestic water use in a rural village in Minas Gerais, Brazil, with an emphasis on spatial patterns, sharing of water and factors in water use. Cad Saúde Públ 14: 109-118.

Gazzinelli A, Souza MCC, Nascimento I, Kloos H 1997. Schistosomiasis, water contact and socioeconomic, water supply and spatial factors in a rural village in Brazil: Methodological aspects, p. 53. Abstracts of the 6th International Symposium on Schistosomiasis, Belo Horizonte.

Hunter JM 1981. Past explosion and future threat: exacerbation of red water disease (schistosomiasis haematobium) in the Upper Region of Ghana. GeoJournal 5.4: 305-313.

Katz N, Chaves A, Pellegrino JP 1972. A simple device for quantitative thick-smear technique in schistosomiasis mansoni. Rev Inst Med Trop São Paulo 14: 397-400.

Kloetzel K 1989. Schistosomiasis in Brazil: does social development suffice? Parasitol Today 5: 388-391

Kloos H 1995. Human behavior, health education and schistosomiasis control. Soc Sci Med 40: 14971511.

Kloos H, Fulford ACA, Butterworth AE, Sturrock RF, Ouma JM, Kariuki HC, Thiongo FW, Dalton PR, Klumpp RK 1997. Spatial patterns of human water contact and Schistosoma mansoni transmission and infection in four rural areas in Machakos District, Kenya. Soc Sci Med 44: 949-968.

Kloos H, Gardiner CH, Selim A, Higashi GI 1982a. Laboratory and field evaluation of a direct filtration technique, with an emphasis on the epidemiology of S. haematobium infection in an Upper Egyptian village. Am J Trop Med Hyg 31: 122-127.

Kloos H, Higashi GI, Cattani JA, Schinski VD, Mansour NS, Murrell KD 1983. Water contact behavior and schistosomiasis in an Upper Egyptian village Soc Sci Med 17: 545-562.

Kloos H, Lo CT, Birrie H, Ayele T, Tedla S, Tsegay F 1988. Schistosomiasis in Ethiopia. Soc Sci Med 26: 803-827.

Kloos H, Sidrak W, Michael AAM, Mohareb EM, Higashi GI 1982b. Disease concepts and medical practices in relation to schistosomiasis haematobium in Upper Egypt. J Trop Med Hyg 85: 99-107.

Lima e Costa MF, Magalhães MHA, Rocha RS, Katz NA 1985. A clinico-epidemiological survey of schistosomiasis mansoni in a hyperendemic area in Minas 
Gerais State (Comercinho, Brazil) 1. Differences in the manifestations of schistosomiasis in the town center and the environs. Trans R Soc Trop Med Hyg 79: 539-545.

Lima e Costa MF, Rocha RS, Leite MLC, Carneiro RG, Colley D, Gazzinelli G, Katz N 1991. A multivariate analysis of socio-demographic factors, water contact patterns and Schistosoma mansoni infection in an endemic area in Brazil. Rev Inst Med Trop $S$ Paulo 33: 58-63.

Malone JB, Huh OK, Fehler DP, Wilson PA, Wilensky DE, Holmes RA, Elmagdoub AI 1994. Temperature data from satellite imagery and the distribution of schistosomiasis in Egypt. Am J Trop Med Hyg 50: 714-722.

Mott KE, Nuttal I, Cattand P 1995. New geographical approaches to control of some parasitic diseases. Bull WHO 73: 247-257.
Sturrock RF, Klumpp RK, Ouma JH, Butterworth AE, Fulford AJC, Kariuki HC, Thiongo FW, Koech D 1994. Observations on the effect of different chemotherapy strategies on the transmission of Schistosoma mansoni in Machakos District, Kenya. Parasitol 109: 443-453.

Van Zuyle P 1995. Modeling Schistosomiasis Using New Tools to Explore the Relationship between Human Behavior and Water-borne Disease, MSc Thesis, Dept. of Geography, University of California, Santa Barbara, 54 pp.

White GF, Bradley DJ, White AU 1972. Drawers of Water: Domestic Water Use in East Africa, University of Chicago Press, Chicago and London, 306 pp.

WHO 1979. Workshop on the role of human/water contact in schistosomiasis transmission and control. WHO Document TDR/SER/HWC/1979.3. World Health Organization, Geneva, 52 pp. 